\title{
A Medicina Baseada nos Brasileiros *
}

\author{
Paulo Andrade Lotufo
}

São Paulo, SP

Médicos brasileiros, quando escrevem em revistas nacionais de divulgação científica ou na imprensa leiga, com freqüência, omitem a realidade do país ou a substituem pelas estatísticas de outros países, na sua maior parte dos Estados Unidos. Enquanto alguns colegas desconhecem o próprio país, a revista Science, em uma reportagem sobre a obesidade em todo o mundo, mostrou os dados brasileiros referentes às décadas de 70 e 80 , com elogios, afirmando ser um dos poucos países com medidas em duas décadas seguidas (considerando a recente pesquisa de 1996, foram três medidas consecutivas).

No momento, não cabe discutir as causas desse comportamento nem as diferenças entre o Brasil e os países mais citados, mas, sim, mostrar que temos informação suficiente para um planejamento adequado das ações de saúde, estruturação da assistência médica e organização da educação médica a partir dos dados colhidos pelo Instituto Brasileiro de Geografia e Estatística (IBGE), pelo Ministério da Saúde, por meio do sistema de informação do Sistema Unificado de Saúde (Datasus) e do Instituto Nacional do Câncer (InCa), como também por vários trabalhos originais ou de revisão publicados em português ou inglês nas mais variadas revistas e livros. Desses, destaco adiante três obras ${ }^{1,2,3}$, cuja riqueza de dados e de análise são, acredito, de consulta obrigatória, além de periódicos como Arquivos Brasileiros de Cardiologia, Cadernos de Saúde Pública, Informativo Epidemiológico do SUS e Revista de Saúde Pública que sempre, em suas páginas, fornecem valiosas informações.

Informações demográficas - A principal base de dados em nosso país é o Censo Demográfico realizado pelo IBGE (www.ibge.gov.br) que fornece as informações básicas para o planejamento em saúde como estrutura etária, razão de masculinidade, frequiência de analfabetos, acesso à água encanada, rede de esgoto, coleta de lixo. Ainda na esfera do

Correspondência: Paulo Andrade Lotufo - Rua Paris, 381 - 01256-040 -

São Paulo, SP - E-mail: bensenor.lotufo@uol.com.br

* Reproduzido de Diagnóstico \& Tratamento 2000; 3: 5-7, com autorização do autor e da revista.
IBGE, há duas fontes de dados de grande valia: a Pesquisa Nacional de Amostra Domiciliar (PNAD) que completa o Censo, e a Pesquisa de Orçamento Familiar (POF), em que há informações valiosas como, por exemplo, as relacionadas ao consumo de alimentos, que permitem avaliar o perfil do padrão dietético da população, além do consumo de cigarros e bebidas alcoólicas. Outras pesquisas, não regulares do IBGE, como a Pesquisa de Padrão de Vida (PPV), de 1996, obteve dados sobre peso e altura e uma inédita pesquisa sobre a atividade física nas regiões metropolitanas.

Estatísticas de saúde - O Datasus, órgão do Ministério da Saúde, protagonizou um dos maiores avanços na coleta, sistematização e divulgação de dados na área da saúde. Com sede no Rio de Janeiro e sub-sedes nas capitais, herdou parte da estrutura do antigo INAMPS, conseguindo prover por meio do seu homesite (www.datasus.gov.br) informações sobre mortalidade, internações, consultas ambulatoriais, procedimentos de alto custo, além dos dados do Censo adaptados às divisões geográficas das secretarias estaduais e municipais de saúde. Sem qualquer exagero, é possível afirmar que somente com as informações do Datasus é possível realizar um número grande de estudos epidemiológicos e de planejamento em saúde.

Mortalidade-Entre as principais informações existentes no site do Datasus, encontram-se as referentes a mortalidade. A sua sistematização é fruto do paciente trabalho iniciado em meados dos anos 70 para prover o país de um sistema de informação de mortalidade integrado e existente em todo o mundo. OCentro Brasileiro de Classificação de Doenças, órgão da Universidade de São Paulo, conveniado ao Ministério da Saúde, durante aquele período implantou as novas revisões da Classificação Internacional de Doenças (CID) e orientou a formação de uma sistematização própria de óbitos (a CID-BR). As secretaria estaduais e o Ministério condensaram nesse período toda a informação proveniente das declarações de óbito que hoje está disponível no site. O sistema de mortalidade recebe críticas por se basear em atestados de óbito, como se esse fato fosse exclusivo do Brasil. Nesse ponto, há que se diferenciar qualidade da sistema- 
tização e qualidade da informação básica. Sistematização é a capacidade do classificador, lendo o atestado, de apontar a causa básica do óbito. Esse não é o problema, mesmo porque estando em parte informatizada, a classificação manual no país dos atestados de óbito já tinha se mostrado de boa qualidade em análises de consistência interna e de comparação externa. A maior limitação do sistema de informação de mortalidade é a subnumeração de óbitos que ainda ocorre em zonas rurais e da declaração do óbito sem assistência médica. Um fato que mostra as diferenças regionais no acesso à assistência médica é o exemplo do Estado da Bahia, onde a proporção de óbitos sem assistência médica para todo o estado é de $25,3 \%$, enquanto que na capital, Salvador, a porcentagem se reduz a $0,3 \%$. De certa forma, essa limitação do sistema não deixa de nos informar um dado fundamental: não há assistência médica em várias áreas do país.

\section{Doenças cardiovasculares, renais, hipertensão e dia-} betes - As doenças cardiovasculares podem ser avaliadas nas estatísticas de mortalidade ou nos procedimentos invasivos pagos pelos SUS. Tal como em outros países, não há registro de casos, seja de infarto do miocárdio ou de acidente vascular cerebral, devido ao grande número de eventos, às reincidências e às dificuldades de definição do caso. Registros existentes, localizados nos países nórdicos, estão restritos a cidades ou a províncias e, nos Estados Unidos, há somente um local que coleta esses dados de forma sistemática (Rochester, Minnesota), mesmo assim em bases amostrais. Os estudos de prevalência de hipertensão somam mais de uma dezena, em várias cidades do país, em momentos diferentes e em faixas etárias não superponíveis. Apesar desses fatos tornarem difíceis um cálculo da prevalência exata para o país como um todo, as revisões sistemáticas com os dados existentes tornaram possível a avaliação da dimensão do problema em termos nacionais. A prevalência da hipercolesterolemia foi estudada em poucos lugares, como Porto Alegre (RS) e São José do Rio Preto (SP), além de outras enquetes em populações selecionadas, todas publicadas nos Arquivos Brasileiros de Cardiologia. $\mathrm{O}$ diabetes foi uma das doença melhor estudadas com a pesquisa de prevalência com metodologia única nas principais capitais, realizada pelo Ministério da Saúde no final da década de 80. Os resultados dessa pesquisa estão disponíveis em várias publicações e constituem um dos melhores materiais epidemiológicos disponíveis no país.

Uma situação muito bem documentada é a insuficiência renal crônica que, apesar de não afligir um grande contingente de brasileiros, é muito onerosa com o tratamento dialítico e transplantes. Há duas fontes importantes de dados; uma, o Datasus, que informa os gastos com o tratamento por região, e a Sociedade Brasileira de Nefrologia (com o apoio da Escola Paulista de Medicina) que criou um registro dos casos de insuficiência renal terminal, abrangente, atualizado e passível de comparação internacional (www.emp.br/ medicina/registro/rgbrint.htm).

Câncer - A contagem dos casos novos de câncer (incidência) é menos complicada e trabalhosa do que a das doenças cardiovasculares, pelo número menor de eventos, e por que há um momento de definição da doença (exame patológico) que propicia maior segurança para o registro. Tal como na maioria dos países com dimensões continentais, o Brasil trabalha com centros representativos das macroregiões (Belém, Fortaleza, Goiânia, Campinas e Porto Alegre) que propiciam os registros de câncer com base populacional. Esses dados permitirão estimar o número provável de novos casos no país, a ordenação dos principais cânceres por localização anatômica, as diferenças por sexo e também as diferenças regionais. O Instituto Nacional do Câncer, no Rio de Janeiro, é o responsável pela sistematização e publicação dos principais dados, inclusive a previsão do número de casos (inca.org.br).

Doenças transmissíveis e vacinação - As doenças infecciosas estão contempladas em vários sites do Ministério e das secretarias estaduais. O principal local de consulta é o Centro Nacional de Epidemiologia (www.fns.gov.br/ cenepi) que publica o Boletim Epidemiológico em que estão registrados os casos de doenças de notificação compulsória. Além desses dados, o site informa a rede de laboratórios de saúde pública, vigilância ambiental, saúde indígena e cobertura de imunizações.

Considerações finais - Com o uso da internet é possível que uma quantidade enorme de dados, que antes se encontravam nas bibliotecas ao alcance de poucos, possam ser acessados em qualquer lugar do planeta. Um epidemiologista que nunca tenha pisado o solo brasileiro, conhecendo um pouco da língua portuguesa, conseguirá traçar um perfil epidemiológico da população nacional com relativa precisão. É evidente que "novas pesquisas serão necessárias" e que "há muito ainda a ser conhecido"; porém, fica difícil entender porque tantas vezes lemos e ouvimos frases do tipo: "como no Brasil não temos dados, o infarto do miocárdio mata 500 mil americanos por ano...”.

\section{Referências}

Os muitos Brasis, Maria Cecília Minayo (FIOCRUZ, RJ), HUCITEC, 1995. Velhos e Novos Males do Brasil, Carlos Augusto Monteiro(FSP-USP), HUCITEC, 1995.
3. O Adulto Brasileiro e as Doenças da Modernidade, Inês Lessa (ISC-UFBa), HUCITEC, 1998. 